Provided for non-commercial research and education use. Not for reproduction, distribution or commercial use.

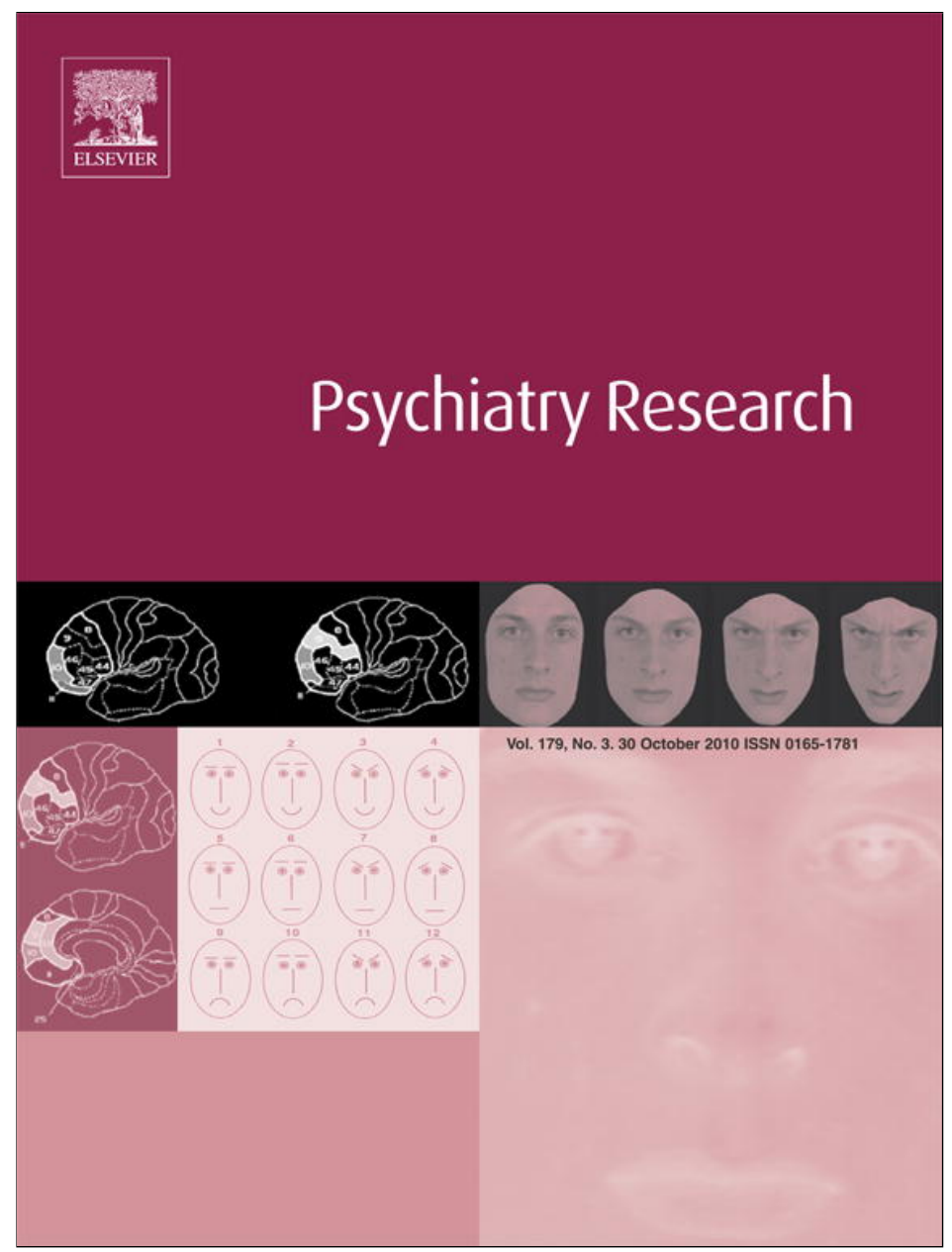

This article appeared in a journal published by Elsevier. The attached copy is furnished to the author for internal non-commercial research and education use, including for instruction at the authors institution and sharing with colleagues.

Other uses, including reproduction and distribution, or selling or licensing copies, or posting to personal, institutional or third party websites are prohibited.

In most cases authors are permitted to post their version of the article (e.g. in Word or Tex form) to their personal website or institutional repository. Authors requiring further information regarding Elsevier's archiving and manuscript policies are encouraged to visit:

http://www.elsevier.com/copyright 


\title{
Prospective memory in non-psychotic first-degree relatives of patients with schizophrenia
}

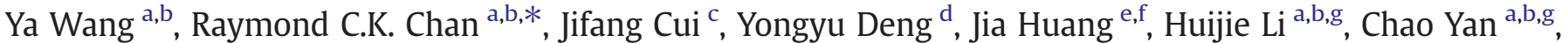 \\ Ting Xu ${ }^{\mathrm{a}, \mathrm{b}, \mathrm{g}}$, Zheng Ma ${ }^{\mathrm{h}}$, Xiaohong Hong ${ }^{\mathrm{i}}$, Zhanjiang $\mathrm{Li}^{\mathrm{h}}{ }^{\text {, Haisong Shi }}{ }^{\mathrm{j}}$, David Shum ${ }^{\mathrm{k}}$ \\ ${ }^{a}$ Neuropsychology and Applied Cognitive Neuroscience Laboratory, Institute of Psychology, Chinese Academy of Sciences, Beijing, China \\ ${ }^{\mathrm{b}}$ Key Laboratory of Mental Health, Institute of Psychology, Chinese Academy of Sciences, Beijing, China \\ c School of Psychology, Beijing Normal University, Beijing, China \\ d Guangdong Vocational College of Mechanical and Electrical Technology, Guangzhou, China \\ e Neuropsychology and Applied Cognitive Neuroscience Laboratory, Department of Psychology, Sun Yat-Sen University, Guangzhou, China \\ ${ }^{\mathrm{f}}$ School of Life Sciences, Sun Yat-Sen University, Guangzhou, China \\ g Graduate School of Chinese Academy of Sciences, Beijing, China \\ h Beijing Anding Hospital, Capital Medical University, Beijing, China \\ ${ }^{i}$ Mental Health Center, Shantou University, Shantou, China \\ ${ }^{\mathrm{j}}$ North China Electric Power University, Beijing, China \\ ${ }^{\mathrm{k}}$ School of Psychology and Griffith Institute for Health and Medical Research, Griffith University, Brisbane, Australia
}

\section{A R T I C L E I N F O}

\section{Article history:}

Received 17 March 2009

Received in revised form 16 June 2009

Accepted 15 July 2009

\section{Keywords:}

Schizophrenia

Prospective memory

Non-psychotic

First-degree relative

\begin{abstract}
A B S T R A C T
Although a number of studies have found prospective memory (PM) impairment in patients with schizophrenia, very little is known about the PM performance in non-psychotic relatives of these patients. The current study aimed to explore the PM performance in non-psychotic first-degree relatives of these patients. Two groups of participants (26 non-psychotic first-degree relatives of schizophrenia patients and 26 healthy comparison participants) were administered three PM tasks (time-, event-, and activity-based) and a set of neurocognitive tests. Results showed that the relatives performed significantly worse than the comparisons on most indices of the PM tasks, with a similar pattern of impairment found in other neurocognitive measures. Together with findings from previous studies, results of the current study suggest that PM may be a potential endophenotype for schizophrenia.
\end{abstract}

(c) 2009 Elsevier Ireland Ltd. All rights reserved.

\section{Introduction}

Studies suggest that schizophrenia may be heritable (Kendler and Diehl, 1993). First-degree non-psychotic relatives of schizophrenia patients have been reported to have a higher rate in developing psychosis than the general population (Gottesman, 1991, 1993). Neurocognitive disorder, as one of the core deficits in schizophrenia, is also heritable. First-degree non-psychotic relatives of schizophrenia patients have also been found to show similar but milder degree neurocognitive impairments (Cannon et al., 2000; Gottesman and Shields, 1982; Kendler and Diehl, 1993; Tuulio-Henriksson et al., 2002).

Results of meta-analyses (Heinrichs and Zakzanis, 1998) indicate that schizophrenia patients have a wide range of neurocognitive disorders. Among them, memory impairment is one that has been studied extensively (Aleman et al., 1999; Lee and Park, 2005; Pelletier

* Corresponding author. Institute of Psychology, Chinese Academy of Sciences, 4A Datun Road, Beijing 100101, China. Tel./fax: +8610 64836274.

E-mail addresses: rckchan@psych.ac.cn, rckchan2003@yahoo.com.hk (R.C.K. Chan). et al., 2005; Piskulic et al., 2007). This type of impairment is also evident in first-degree non-psychotic relatives of schizophrenia (Sitskoorn et al., 2004; Szokr et al., 2005; Trandafir et al., 2006; Whyte et al., 2005). However, all of these studies were limited to the study of retrospective memory (RM) rather than prospective memory (PM).

PM refers to the ability to remember to carry out an intended action in the future (Brandimonte et al., 1996). It is considered important for daily living. Everyday functionings such as remembering to turn up for an appointment and make a phone call at the right time, all require good working of PM. In addition, failures of PM such as forgetting to take medication or forgetting to turn off the oven after cooking could have dire consequences (Shum et al., 2001).

PM can be divided into three types according to the nature of the cues associated with the planned delayed intention (Einstein and McDaniel, 1990; Kvavilashvili and Ellis, 1996). Time-based PM refers to remembering to execute an intention at a specific time or after a period of time (e.g., remember to attend a meeting at 10:00am on Tuesday); eventbased PM refers to remembering to execute an intention when an event/ cue appears (e.g., remember to give a message to a friend upon his/her 
appearance); and activity-based PM refers to remembering to execute an intention after completion of an activity (e.g., remember to answer an email after lunch).

Among the studies that examined PM in individuals with schizophrenia, their findings consistently showed that these patients are impaired on PM, irrespective of subtypes (Chan et al., 2008b; Elvevag et al., 2003; Henry et al., 2007; Kondel, 2002; Kumar et al., 2005, 2008; Shum et al., 2004; Twamley et al., 2008; Wang et al., 2008a,b; Woods et al., 2007). Furthermore, some of these studies have found that PM impairment in these patients persist even after controlling for other neurocognitive disorders, suggesting that PM impairment is a primary rather than secondary deficit of schizophrenia (Henry et al., 2007; Wang et al., 2008a). In terms of the nature of impairment, some of these studies suggest that the PM impairments in these patients mainly occur at the cue detection and intention retrieval stages (Wang et al., 2008a; Woods et al., 2007), and others suggest that subjective PM complaints may be dissociated from objective PM performances (Chan et al., 2008b)

We know about the cognitive profiles of first-degree relatives of schizophrenia patients on verbal and visual memory, working memory, attention, and executive functions. Basically, this group of individuals has been found to perform significantly more poorly than matched controls on these functions but their level of performance was not as severe as patients with schizophrenia. However, the performance of PM in this population has not been studied yet. This study will provide information on the PM performance in this group of individuals. By studying PM in relatives of schizophrenia patients, we can identify whether PM would be an endophenotypic marker of schizophrenia and can lead to further genetic studies. In addition, we can provide cognitive remediation therapy to improve the PM difficulties in this high risk group. The present study, therefore, aimed to explore the PM performance in these relatives. We hypothesized that the relatives would perform significantly more poorly than the comparison group.

\section{Methods}

\subsection{Participants}

Twenty-six first-degree non-psychotic relatives (14 parents and 12 siblings) of schizophrenia patients were recruited, one relative from each patient. All the patients fulfilled the Diagnostic and Statistical Manual of Mental Disorders, fourth edition (DSM-IV American Psychiatric Association, 1994) diagnostic criteria for schizophrenia based on diagnostic interviewing (using the Structural Clinical Interview for DSM-IV and medical record reviews). These relatives were recruited from two regional psychiatric hospitals in China (Mental Health Center of Shantou University \& Beijing Anding Hospital of Capita Medical University). Relatives were interviewed by psychiatrists to ensure that they dic not have psychiatric illness, history of neurological illness, or drug/alcohol dependence. None of the participants reported had human immunodeficiency syndrome (HIV) infection.

Twenty-six healthy participants were also recruited as comparison group from three universities and the general community. A semi-structured interview was conducted by a trained research assistant to ensure that none of the comparison group had any family history of psychiatric illness, suffered from neurological illness, or had alcohol/drug dependence.

Intellectual functioning was estimated using the four-subtest (viz., information, arithmetic, similarity, and digit span) short-form of the Chinese version of the Wechsler Adult Intelligence Scale-Revised (WAIS-R)(Gong, 1992). Handedness was assessed by the Annett Handedness Scale (Spreen and Strauss, 1991). Demographic information of the

Table 1

Demographic and clinical data of participants.

\begin{tabular}{|c|c|c|c|c|c|c|}
\hline & \multicolumn{2}{|c|}{$\begin{array}{l}\text { Relative } \\
(N=26)\end{array}$} & \multicolumn{2}{|c|}{$\begin{array}{l}\text { Control } \\
(N=26)\end{array}$} & \multirow[t]{2}{*}{$\begin{array}{l}F(1,50) / \\
\chi^{2}(1)\end{array}$} & \multirow[t]{2}{*}{$P$} \\
\hline & Mean & S.D. & Mean & S.D. & & \\
\hline Male: female & $18: 8$ & & $18: 8$ & & 0 & 1 \\
\hline Right handed percentage & 92 & & 96 & & 1.33 & 0.513 \\
\hline Age (years) & 50.02 & 13.66 & 43.38 & 11.54 & 3.58 & 0.064 \\
\hline Education (years) & 11.71 & 2.92 & 11.15 & 2.98 & 0.47 & 0.498 \\
\hline IQ & 108.42 & 12.93 & 98.31 & 16.13 & 6.23 & 0.016 \\
\hline
\end{tabular}

Gender and handedness used $\chi^{2}$ test. participants is shown in Table 1 . Age, education, and gender ratio were not significantly different between the two groups but intelligence quotient (IQ) was $[F(1,50)=6.23$, $P=0.016]$. The present study was approved by the ethics committees of the corresponding institutions. Written informed consent was obtained from each participant.

\subsection{Measures}

\subsubsection{PM tasks}

Detailed description of the three PM tasks used in this study has been included in our previous studies (Chan et al 2008b; Wang et al 2008ab). Briefly, there were two versions of the task (i.e., semantic and perceptual) in order to control for semantic memory. In the semantic event-based PM (se_ev) session, a four-character phrase (in Chinese) was presented in the center of the screen and the participants were asked to judge whether the phrases were idioms or not. They were asked to press the "J" key to answer affirmatively and the " $F$ " key to answer negatively (this was defined as the ongoing task). If there was an animal character in the phrase (e.g., horse), they were asked to press the spacebar (this was defined as the PM task). A total of five animal characters appeared during the session and the time interval between the appearances of each animal character was approximately $1 \mathrm{~min}$. The participants were told that the two tasks (ongoing task and PM) were of the same importance. There were 88 ongoing task trials and five PM task trials in this session.

The semantic time-based PM (se_ti) session is basically the same as the semantic event-based PM one except that a clock was placed at the upper right part of the keyboard. The participants were asked to monitor the time throughout the testing session. Each time the clock reached the full minute (e.g., 12:23:00, the last two digits are 00), they were asked to press the spacebar (PM task). This session lasted for about 5 $1 / 2$ min. Unlike the semantic event-based session, no animal characters were included in the four-character phrases of this task. There were 90 ongoing task trials and five PM task trials in this session.

The perceptual event-based PM (pe_ev) session is similar to the semantic eventbased one except that the ongoing task involved judging whether a perceptually degraded digit appeared in the center of the screen was a 0 . The participants were asked to press "I" if it was the case and "F" if it was not. On occasions that there was a down arrow under the perceptually degraded digit, the participants were asked to press the spacebar regardless whether the digit was 0 or not, and this was defined as the PM task. There were 122 ongoing task trials and five PM task trials in this session.

The perceptual time-based PM (pe_ti) session is the same as the perceptual eventbased one except that a clock was placed at the upper right part of the keyboard and participants were asked to monitor the clock and press the spacebar at each $1 \mathrm{~min}$ interval. No down arrows was included in any of the trials. There were 135 ongoing task trials and five PM task trials in this session.

At the end of each of the above four sessions, participants would see the phrase "Thank you for your participation! Bye" on the screen and they were instructed to pres the "Enter" key upon seeing this phrase. This was defined as the activity-based PM task The activity-based PM performance was the proportion of time the participants pressing the "Enter" key in all four sessions. For all the time-, event-, and activity-based PM performances, accuracy of PM was recorded.

\subsubsection{Other neurocognitive tests}

A set of neurocognitive tests was also administered to all participants. Details of these tests have also been described elsewhere (Chan et al., submitted; Wang et al., 2008a,b). In brief, verbal and visual memory were assessed by the logical memory and visual reproduction subtests of the Chinese version (Gong et al., 1989) of the Wechsler Memory Scale-Revised (Wechsler, 1987); working memory was assessed by the Chinese version of the Letter-Number Span Test (Chan et al., 2008a) and the 2-back part of the $n$-back task (Callicott et al., 1998), for Letter-Number Span, the total correct number and longest passed item were recorded, for 2-back task, the accuracy and reaction time for correct responses were recorded; sustained attention was evaluated by the Sustained Attention Response to Task (SART) (Robertson et al., 1997), the correct press rate and commission error rate were recorded; executive function was evaluated by the modified Wisconsin Card Sorting Test (WCST) (Nelson,1976) and the animal name semantic verbal fluency task (Spreen and Strauss, 1998), for WCST, categories achieved and perseverative errors were recorded, for verbal fluency task, correct items were recorded.

\subsection{Procedure}

All participants were given a general introduction to the study as well as an opportunity to ask questions about the study. They then signed an informed consent form before testing began. IQ subtests were administered between PM practice and formal testing as a delay activity. The four PM tasks were given in the following randomly generated order for all participants: se_ti, pe_ev, se_ev and pe_ti. Then the neurocognitive tests were administered in a random order

\subsection{Data analysis}

Se_ev and pe_ev PM task performances were averaged to generate an event-based PM score. Se ti and pe ti PM task performances were averaged to generate a timebased PM score. Event-based, time-based, and activity-based PM scores were converted to standardized scores (using save standardized values as variables in SPSS 13.0). These scores were then added up to give a summary PM score Z_PM. 
Multivariate analyses of covariance (MANCOVAs) were performed to examine the group difference in PM measures with IQ used as covariates. This is followed by individual univariate ANCOVAs. In addition, effect sizes (Cohen's $d$ ) were calculated. Next, a series of ANCOVAs was performed to examine the group difference on the neurocognitive function measures administered (verbal and visual memory, working memory, attention, and executive function). Finally, correlation analysis between PM performance and other neurocognitive functions was conducted.

\section{Results}

\subsection{Group difference of PM and other neurocognitive functions}

For MANCOVA test of all PM performance, the group difference was significant, $F(3,47)=4.81, P=0.005$ (Pillai's Trace). Time-based PM $[F(1,49)=9.15, P=0.004]$, event-based PM $[F(1,49)=10.32$, $P=0.002]$, and total PM index Z_PM $[F(1,49)=13.46, P=0.001]$ all had significant group differences. A general profile of the PM performances was the comparison group performed better than nonpsychotic relatives of schizophrenia patients. Several comparisons between relatives and the comparison group reached or approached medium effect sizes (Cohen's $d$ ranged from -0.25 to -0.59 ) (Table 2). All the PM errors in this study were omission errors, which meant that the participants forgot to make PM responses.

For the ongoing task performances, the mean accuracy of ongoing task in event-based PM was 0.88 (S.D. $=0.07)$ for comparison group and 0.82 (S.D. $=0.07$ ) for relatives, and mean accuracy of ongoing task in time-based PM was 0.86 (S.D. $=0.04$ ) for comparison group and 0.81 (S.D. $=0.08$ ) for relatives. Relatives performed significantly worse than comparisons in ongoing task of event-based PM, $F(1,49)=13.34$, $P=0.001$ and time-based PM, $F(1,49)=12.93, P=0.001$. Event-based and time-based PM performance were still significantly different between two groups after controlling for corresponding ongoing task performances, for event-based $P M, F(1,48)=6.22, P=0.016$; and for time-based PM, $F(1,48)=5.09, P=0.029$.

For other neurocognitive measures, significant group differences were found for 2-back accuracy, $[F(1,30)=8.47, P=0.007]$, and WCST perseverative error $[F(1,40)=4.32, P=0.044]$. The same pattern of performance level as in the PM tasks was demonstrated for these neurocognitive tests, that is, the comparison group performed better than relatives (see Table 3 ).

Considering the non-normal distribution of the performances, we also performed non-parametric statistical analysis; Mann-Whitney $U$ test indicated that time-based PM, PM summary score and 2-back accuracy were significantly better in comparison group than in relative group. For time-based PM, $Z=-2.134, P=0.033$; for Z_PM, $Z=-2.408, P=0.016$; for 2-back accuracy, $Z=-1.973, P=0.048$. These results were similar to the former parametric statistical results, so we just present parametric test results in detail.

\subsection{Correlations between PM and other neurocognitive functions}

Correlation analyses showed that significant associations were found between PM tasks and neurocognitive tests that measure visual

Table 2

Comparison of PM performances (control for IQ).

\begin{tabular}{|c|c|c|c|c|c|c|c|}
\hline & \multicolumn{2}{|c|}{$\begin{array}{l}\text { Relative } \\
(N=26)\end{array}$} & \multicolumn{2}{|c|}{$\begin{array}{l}\text { Control } \\
(N=26)\end{array}$} & \multirow[t]{2}{*}{$\mathrm{F}$} & \multirow[t]{2}{*}{$P$} & \multirow[t]{2}{*}{ Cohen's $d$} \\
\hline & Mean & S.D. & Mean & S.D. & & & \\
\hline Time PM & 0.53 & 0.33 & 0.72 & 0.33 & 9.15 & 0.004 & -0.56 \\
\hline Event PM & 0.54 & 0.33 & 0.67 & 0.25 & 10.32 & 0.002 & -0.43 \\
\hline Activity PM & 0.88 & 0.25 & 0.94 & 0.20 & 1.51 & 0.225 & -0.25 \\
\hline Z_PM & -0.20 & 0.68 & 0.20 & 0.71 & 13.46 & 0.001 & -0.59 \\
\hline
\end{tabular}

For the time-, event-, and activity-based PM performances, the table presents the proportion correct of PM task; for the Z_PM (PM summary score), it is the addition of standardized score of three types of PM performances. According to Cohen (Cohen, 1988), Cohen's $d$ more than 0.5 is medium; more than 0.8 is large.
Table 3

Comparison of other neurocognitive performances (control for IQ).

\begin{tabular}{|c|c|c|c|c|c|c|c|c|c|}
\hline & \multicolumn{3}{|c|}{ Relative } & \multicolumn{3}{|c|}{ Control } & \multirow[t]{2}{*}{1} & \multirow[t]{2}{*}{$P$} & \multirow[t]{2}{*}{ Cohen's $d$} \\
\hline & $\bar{N}$ & Mean & S.D. & $\bar{N}$ & Mean & S.D. & & & \\
\hline \multicolumn{10}{|c|}{ Verbal and visual memory } \\
\hline LM_imme & 24 & 10.29 & 4.34 & 24 & 11.50 & 3.97 & 3.19 & 0.081 & -0.29 \\
\hline LM_delay & 24 & 8.42 & 4.41 & 24 & 9.42 & 4.22 & 2.23 & 0.142 & -0.23 \\
\hline VR_imme & 24 & 20.67 & 2.55 & 24 & 21.13 & 4.09 & 3.03 & 0.089 & -0.14 \\
\hline VR_delay & 24 & 19.96 & 3.03 & 24 & 20.50 & 4.65 & 3.63 & 0.063 & -0.14 \\
\hline \multicolumn{10}{|c|}{ Working memory } \\
\hline CLN_corr & 16 & 11.81 & 2.40 & 18 & 12.83 & 3.26 & 3.89 & 0.058 & -0.36 \\
\hline CLN_lg & 16 & 5.13 & 1.09 & 18 & 5.44 & 1.34 & 1.38 & 0.249 & -0.25 \\
\hline 2back_c & 16 & 0.24 & 0.09 & 17 & 0.38 & 0.19 & 8.47 & 0.007 & -0.94 \\
\hline 2back_rt & 16 & 768.38 & 295.70 & 17 & 679.12 & 230.92 & 0.81 & 0.375 & 0.34 \\
\hline \multicolumn{10}{|c|}{ Attention and executive function } \\
\hline SART_hit & 20 & 0.96 & 0.03 & 25 & 0.97 & 0.03 & 1.46 & 0.234 & -0.22 \\
\hline SART_ce & 20 & 0.31 & 0.19 & 25 & 0.30 & 0.16 & 0.86 & 0.36 & 0.09 \\
\hline VF_c & 20 & 19.15 & 5.60 & 25 & 17.68 & 4.98 & 0.11 & 0.747 & 0.28 \\
\hline WCST_pe & 20 & 3.65 & 2.68 & 23 & 2.83 & 2.96 & 4.32 & 0.044 & 0.29 \\
\hline WCST_ca & 20 & 4.40 & 1.73 & 23 & 4.78 & 2.07 & 1.72 & 0.198 & -0.20 \\
\hline
\end{tabular}

LM_imme = logical memory immediate; LM_delay = logical memory delay; VR_imme = visual reproduction immediate; VR_delay = visual reproduction delay; CLN_corr $=$ CLN total correct; $C L N \_l g=$ CLN longest passed; 2 back_c $=2$ back accuracy; 2 back $\_r t=2$ back RT; SART_hit $=$ SART correct press percentage; SART_ce $=$ SART commission error percentage; VF_c = verbal fluency correct; WCST_pe = WCST perseverative error; WCST_ca $=$ WCST category.

According to Cohen (Cohen, 1988), Cohen's $d$ more than 0.5 is medium; more than 0.8 is large.

memory, working memory, sustained attention, and executive function (Table 4).

\section{Discussion}

To the best of our knowledge, this is the first study of PM performance in non-psychotic first-degree relatives of schizophrenia. In accordance with our hypothesis, results indicate that these relatives performed significantly worse than the comparison group on time- and event-based PM tasks, with a similar pattern of performances for other neurocognitive functions. In addition, unlike patients with schizophrenia who were found to be impaired on the activity-based PM task (Chan et al., 2008b; Kumar et al., 2008; Shum et al., 2004; Wang et al., 2008a), the relatives in this study did not show similar impairment. This suggests that first-degree non-psychotic relatives of schizophrenia patients show neurocognitive impairment (including PM) but not as severe as in patients with schizophrenia.

Functional neuroimaging studies have found frontal abnormalities in relatives of schizophrenia patients. For example, relatives of schizophrenia patients showed abnormal activations in prefrontal regions compared to the participants in the comparison group (Whalley et al., 2005); relatives of schizophrenia showed a different activation pattern compared to the participants in the comparison group (MacDonald et al., 2006); individuals at high genetic risk for schizophrenia showed significantly greater activation in right dorsal lateral prefrontal cortex, suggesting that altered dopamine catabolism in the dorsal lateral prefrontal cortex was a genetically transmitted abnormality associated with the functional deficit (Seidman et al., 2006). Given that neuroimaging studies in healthy populations found frontal regions (especially dorsal lateral prefrontal cortex and BA10) were activated when subjects performed PM tasks (Burgess et al., 2001, 2003; den Ouden et al., 2005; Okuda et al., 1998, 2007; Simons et al., 2006), it is understandable that relatives of schizophrenia patients would show impairments in PM. In addition, measures of PM were also found to correlate significantly with other neurocognitive functions (Henry et al., 2007; Wang et al., 2008a), suggesting that other neurocognitive functions may underlie PM 
Table 4

Correlation between PM and other neurocognitive functions for participants.

\begin{tabular}{|c|c|c|c|c|c|c|c|c|c|}
\hline & & Control & & & & Relative & & & \\
\hline & & Time PM & Event PM & Activity PM & Z_PM & Time PM & Event PM & Activity PM & Z_PM \\
\hline LM_imme & $r$ & 0.26 & 0.31 & 0.33 & 0.38 & -0.13 & 0.21 & $-.42^{a}$ & -0.17 \\
\hline & $N$ & 25 & 25 & 25 & 25 & 25 & 25 & 25 & 25 \\
\hline LM_delay & $r$ & 0.34 & $0.40^{\mathrm{a}}$ & 0.35 & $0.46^{\mathrm{a}}$ & -0.18 & 0.17 & $-0.45^{\mathrm{a}}$ & -0.25 \\
\hline & $N$ & 25 & 25 & 25 & 25 & 24 & 24 & 24 & 24 \\
\hline VR_imme & $r$ & $0.49^{a}$ & $0.73^{b}$ & $0.84^{\mathrm{b}}$ & $0.75^{b}$ & 0.24 & $0.52^{b}$ & 0.01 & 0.40 \\
\hline & $N$ & 24 & 24 & 24 & 24 & 25 & 25 & 25 & 25 \\
\hline VR_delay & $r$ & $0.60^{\mathrm{b}}$ & $0.72^{b}$ & $0.63^{b}$ & $0.81^{\mathrm{b}}$ & 0.06 & $0.45^{\mathrm{a}}$ & 0.05 & 0.30 \\
\hline & $N$ & 25 & 25 & 25 & 25 & 24 & 24 & 24 & 24 \\
\hline CLN_corr & $r$ & -0.19 & 0.13 & c & 0.01 & -0.27 & 0.20 & -0.36 & -0.13 \\
\hline & $N$ & 18 & 18 & 18 & 18 & 16 & 16 & 16 & 16 \\
\hline 2back_c & $r$ & 0.39 & 0.22 & c & 0.35 & 0.21 & 0.11 & -0.32 & 0.09 \\
\hline & $N$ & 18 & 18 & 18 & 18 & 17 & 17 & 17 & 17 \\
\hline SART_hit & $r$ & $0.66^{\mathrm{b}}$ & 0.32 & 0.21 & $0.51^{\mathrm{b}}$ & -0.09 & 0.12 & $0.46^{\mathrm{a}}$ & 0.14 \\
\hline & $N$ & 25 & 25 & 25 & 25 & 20 & 20 & 20 & 20 \\
\hline SART_ce & $r$ & -0.35 & $-0.48^{\mathrm{a}}$ & 0.00 & -0.34 & 0.00 & -0.43 & -0.13 & -0.29 \\
\hline & $N$ & 25 & 25 & 25 & 25 & 20 & 20 & 20 & 20 \\
\hline VF_c & $r$ & 0.23 & $0.48^{a}$ & 0.10 & 0.33 & 0.07 & 0.19 & 0.23 & 0.26 \\
\hline & $N$ & 25 & 25 & 25 & 25 & 20 & 20 & 20 & 20 \\
\hline WCST_pe & $r$ & -0.15 & -0.10 & -0.23 & -0.21 & -0.25 & $-0.52^{\mathrm{a}}$ & 0.09 & -0.37 \\
\hline & $N$ & 23 & 23 & 23 & 23 & 20 & 20 & 20 & 20 \\
\hline WCST_ca & $r$ & 0.00 & -0.16 & -0.03 & -0.07 & $0.53^{\mathrm{a}}$ & $0.47^{\mathrm{a}}$ & -0.01 & $0.52^{\circ}$ \\
\hline & $N$ & 23 & 23 & 23 & 23 & 20 & 20 & 20 & 20 \\
\hline
\end{tabular}

LM_imme = logical memory immediate; LM_delay = logical memory delay; VR_imme = visual reproduction immediate; VR_delay $=$ visual reproduction delay; CLN_corr $=$ CLN total correct; CLN_lg = CLN longest passed; 2back_c = 2back accuracy; 2back_rt $=$ 2back RT; SART_hit $=$ SART correct press percentage; SART_ce $=$ SART commission error percentage; VF_c = verbal fluency correct; WCST_pe = WCST perseverative error; WCST_ca $=$ WCST category.

a Indicates $P<0.05$.

b Indicates $P<0.01$.

c Cannot be computed because activity PM is constant in these participants.

process. Nevertheless, studies such as Henry et al. and Wang et al. have found that PM impairment in schizophrenia was not secondary to other neurocognitive impairment. Given the small number of relatives included in this study, it is not possible to clarify if this is also the case for the relatives and further studies with large samples are needed to answer this question.

Results of the present study are consistent with meta-analysis on non-psychotic first-degree relatives of schizophrenia (Sitskoorn et al. 2004; Trandafir et al., 2006) in verbal memory, visual memory, and executive tests (see Table 5, effect sizes are in absolute values, with relatives performed poorer than participants in the comparison group unless otherwise indicated). For working memory, Horan et al. (2008) found that for their large relative sample $(N=324)$ the effect size of Letter-Number Sequencing was 0.36. In the present study, the Chinese version also had an effect size of 0.36. In general, the results of the present study are consistent with previous studies and meta-analyses that showed relatives of schizophrenia patients have a wide range of neurocognitive impairments and they had less severe deficits compared to patients. For PM, the effect size of combined PM indices ranged from 0.25 to 0.59 and it is similar to other neurocognitive measures, suggesting that the relatives of patients with schizophrenia have a moderate PM impairment, and their level of impairment is comparable to that of other neurocognitive deficits.

Together with results from previous studies (Chan et al., 2008b; Henry et al., 2007; Shum et al., 2004; Wang et al., 2008a,b; Woods et al., 2007), the findings of this study suggest that PM may be a potential endophenotype of schizophrenia. This is of importance for researchers: endophenotypes lie nearer to the neurobiology of disease, thus it would be more straightforward to search for the genetic determinants of schizophrenia using the endophenotype approach (Chan and Gottesman, 2008; Gottesman and Gould, 2003).

For the correlations between PM and other neurocognitive functions, PM was significantly correlated with memory and executive functions, which was consistent with previous studies on schizophrenia patients (Henry et al., 2007; Shum et al., 2004). In the firstdegree relatives, visual memory was found to correlate with eventbased but not time-based PM. This may be because event-based PM of this study required visual search of the animal names in the semantic condition and visual retention of the down arrow in the perceptual condition. In contrast time-based PM of this study did not involve such functions. This veracity of this explanation, however, needs to be confirmed by further studies.

Table 5

Comparisons of effect size between the present study and meta-analysis.

\begin{tabular}{llll}
\hline Measures & Meta-analysis & Meta-analysis effect size \\
\hline Logical memory immediate & Trandafir et al. (2006) & 0.47 \\
Logical memory delay & Trandafir et al. (2006) & 0.38 \\
Visual reproduction immediate & Trandafir et al. (2006) & 0.17 & 0.29 \\
Visual reproduction delay & Trandafir et al. (2006) & 0.24 & 0.23 \\
Verbal fluency correct & Sitskoorn et al. (2004) & 0.35 & 0.14 \\
Wisconsin Card Sorting Test & Sitskoorn et al. (2004) & 0.14 \\
\hline
\end{tabular}

\footnotetext{
${ }^{a}$ Relatives generate more words than controls in the present study.
} 
There are several limitations in the present study. First, the sample size of the relative group is small and more participants should be recruited in future studies. Second, parents and siblings of schizophrenia patients were not analyzed separately due to the small sample size. Instead, we tried to match the two samples according to age and gender. This is mainly due to the one-child policy introduced in China in the late 1970 s, persons born after the 1980s do not usually have siblings. Therefore, it is difficult to recruit a large number of siblings of schizophrenia research for a study like this in China.

Notwithstanding these limitations, the current study presented promising data on PM performance of non-psychotic first-degree relatives of patients with schizophrenia and suggests that PM may be a potential endophenotype for schizophrenia. To corroborate these findings, future studies adopting a more rigorous design and recruiting a larger sample are needed.

\section{Acknowledgments}

This study was supported partially by the Research Initiation Fund (113000C151), and Young Investigator Scientific Fund (O9CX073007) of Institute of Psychology, Chinese Academy of Sciences, and the Research Initiation Fund (O7CX031003) and the Knowledge Innovation Project of the Chinese Academy of Sciences (KSCX2-YW-R-131), and the National Basic Research Programme (973 Programme No. 2007CB512302). These funding agents had no further role in the study design; in the collection, analysis and interpretation of the data; in the writing of the manuscript; and in the decision to submit the paper for publication.

\section{References}

Aleman, A., Hijman, R., de Haan, E.H.F., Kahn, R.S., 1999. Memory impairment in schizophrenia: a meta-analysis. The American Journal of Psychiatry 156,1358-1366. American Psychiatric Association, 1994. Diagnostic and Statistical Manual of Mental Disorders, 4th ed. American Psychiatric Association, Washington, DC.

Brandimonte, M., Einstein, G.O., McDaniel, M.A. (Eds.), 1996. Prospective Memory: Theory and Applications. Lawrence Erlbaum Associates, Mahwah, New Jersey.

Burgess, P.W., Quayle, A., Frith, C.D., 2001. Brain regions involved in prospective memory as determined by positron emission tomography. Neuropsychologia 39, 545-555.

Burgess, P.W., Scott, S.K., Frith, C.D., 2003. The role of the rostral frontal cortex (area 10) in prospective memory: a lateral versus medial dissociation. Neuropsychologia 41 , 439-453.

Callicott, J.H., Ramsey, N.F., Tallent, K., Bertolino, A., Knable, M.B., Coppola, R., Weinberger, D.R., 1998. Functional magnetic resonance imaging brain mapping in psychiatry: methodological issues illustrated in a study of working memory in schizophrenia. Neuropsychopharmacology 18, 186-196.

Cannon, T.D., Huttunen, M.O., Lonnqvist, J., Tuulio-Henriksson, A., Pirkola, T., Glahn, D., Finkelstein, J., Hietanen, M., Kapriol, J., Koskenvuno, M., 2000. Inheritance of neuropsychological functions in twins discordant for schizophrenia. American Journal of Human Genetics 67, 369-382.

Chan, R.C.K., Gottesman, I.I., 2008. Neurological soft signs as candidate endophenotypes for schizophrenia: a shooting star or a Northern star? Neuroscience and Biobehavioral Reviews 32, 957-971

Chan, R.C.K., Wang, Y., Deng, Y., Zhang, Y., Yiao, X., Zhang, C., 2008a. The development of a Chinese equivalence version of Letter-Number Span Test. The Clinical Neuropsychologist 22, 112-121.

Chan, R.C.K., Wang, Y., Ma, Z., Hong, X., Yuan, Y., Yu, X., Li, Z., Shum, D., Gong, Q., 2008b. Objective measures of prospective memory do not correlate with subjective complaints in schizophrenia. Schizophrenia Research 103, 229-239.

Chan, R.C.K., Qing, Y., Wu, Q., submitted for publication. Subjective complaints of prospective and retrospective memory in normal aging: A confirmatory factor analytical study.

Cohen, J., 1988. Statistical Power Analysis for the Behavioral Sciences, 2nd ed. Lawrence Earlbaum Associates, Hillsdale, NJ.

den Ouden, H.E.M., Frith, U., Frith, C.D., Blakemore, S.J., 2005. Thinking about intentions. Neuroimage 28, 787-796.

Einstein, G.O., McDaniel, M.A., 1990. Normal aging and prospective memory. Journal of Experimental Psychology: Learning, Memory, and Cognition 16, 717-726.

Elvevag, B., Maylor, E.A., Gilbert, A.L., 2003. Habitual prospective memory in schizophrenia. BMC Psychiatry 3.

Gong, Y.X., 1992. Manual of Wechsler Adult Intelligence Scale-Chinese Version. Chinese Map Press, Changsha.

Gong, Y.X., Gong, Y.X., Jiang, D.W., Deng, J.L., Dai, Z.S., Zhou, Q.Z., Xie, G.R., Li, Y., Hua, X.X., 1989. Manual of Wechsler Memory Scale-Chinese Version. Hunan Medical College Press, Changsha.

Gottesman, I.I. 1991. Schizophrenia Genesis: the Origin of Madness. Freeman, New York.

Gottesman, I.I., 1993. Origins of schizophrenia: past as prologue. In: Plomin, R., McClearn, G.E. (Eds.), Nature Nurture and Psychology. American Psychological Association, Washington, DC, pp. 231-244.

Gottesman, I.I., Shields, J., 1982. Schizophrenia. The Epigenetic Puzzle. Cambridge University Press, Cambridge.
Gottesman, I.I., Gould, T.D., 2003. The endophenotype concept in psychiatry: etymology and strategic intentions. American Journal of Psychiatry 160, 636-645.

Heinrichs, R.W., Zakzanis, K.K., 1998. Neurocognitive deficit in schizophrenia: a quantitative review of the evidence. Neuropsychology 12, 426-445.

Henry, J.D., Rendell, P.G., Kliegel, M., Altgassen, M., 2007. Prospective memory in schizophrenia: primary or secondary impairment? Schizophrenia Research 85, 179-185.

Horan, W.P., Braff, D.L., Nuechterlein, K.H., Sugar, C.A., Cadenhead, K.S., Calkins, M.E., Dobie, D.J., Freedman, R., Greenwood, T.A., Gur, R.E., Gur, R.C., Light, G.A., Mintz, J., Olincy, A., Radant, A.D., Schork, N.J., Seidman, L.J., Siever, L.J., Silverman, J.M., Stone, W.S., Swerdlow, N.R., Tsuang, D.W., Tsuang, M.T., Turetsky, B.I., Green, M.F., 2008. Verbal working memory impairments in individuals with schizophrenia and their first-degree relatives: findings from the Consortium on the Genetics of Schizophrenia. Schizophrenia Research 103, 218-228.

Kendler, K.S., Diehl, S.R., 1993. The genetics of schizophrenia: a current, geneticepidemiologic perspective. Schizophrenia Bulletin 19, 261-285.

Kondel, T.K., 2002. Prospective memory and executive function in schizophrenia. Brain and Cognition 48, 405-410.

Kumar, D., Nizamie, S.H., Jahan, M., 2005. Event-based prospective memory in schizophrenia. Journal of Clinical \& Experimental Neuropsychology 27, 867-872.

Kumar, D., Nizamie, S.H., Jahan, M., 2008. Activity-based prospective memory in schizophrenia. The Clinical Neuropsychologist 22, 497-506.

Kvavilashvili, L., Ellis, J.A., 1996. Variety of intentions: some distinctions and classifications. In: Brandimonte, M., Einstein, G.O., McDaniel, M.A. (Eds.), Prospective Memory: Theory and Applications. LEA, Mahwah, NJ, pp. 23-52.

Lee, J., Park, S., 2005. Working memory impairments in schizophrenia: a meta-analysis. Journal of Abnormal Psychology 114, 599-611.

MacDonald, A.W., Becker, T.M., Carter, C.S., 2006. Functional magnetic resonance imaging study of cognitive control in the healthy relatives of schizophrenia patients. Biological Psychiatry 60, 1241-1249.

Nelson, H.E., 1976. A modified card sorting task sensitive to frontal lobe defects. Cortex 12, 313-324.

Okuda, J., Fujii, T., Yamadori, A., Kawashima, R., Tsukiura, T., Fukatsu, R., Suzuki, K., Ito, M., Fukuda, H., 1998. Participation of the prefrontal cortices in prospective memory: evidence from a PET study in humans. Neuroscience Letters 253, 127-130.

Okuda, J., Fujii, T., Ohtake, H., Tsukiura, T., Yamadori, A., Frith, C.D., Burgess, P.W., 2007. Differential involvement of regions of rostral prefrontal cortex (Brodmann area 10) in time- and event-based prospective memory. International Journal of Psychophysiology 64, 233-246.

Pelletier, M., Achim, A.M., Montoya, A., Lal, S., Lepage, M., 2005. Cognitive and clinical moderators of recognition memory in schizophrenia: a meta-analysis. Schizophrenia Research 74, 233-252.

Piskulic, D., Olver, J.S., Norman, T.R., Maruff, P., 2007. Behavioural studies of spatial working memory dysfunction in schizophrenia: a quantitative literature review. Psychiatry Research 150, 111-121.

Robertson, H., Manly, T., Andrade, J., Baddeley, B.T., Yiend, J., 1997. “Oops!”: performance correlates of everyday attentional failures in traumatic brain injured and normal subjects. Neuropsychologia 35.

Seidman, L.J., Thermenos, H.W., Poldrack, R.A., Peace, N.K., Koch, J.K., Faraone, S.V., Tsuang, M.T., 2006. Altered brain activation in dorsolateral prefrontal cortex in adolescents and young adults at genetic risk for schizophrenia: an fMRI study of working memory. Schizophrenia Research $85,58-72$.

Shum, D., Leung, J.P., Ungvari, G.S., Tang, W.K., 2001. Schizophrenia and prospective memory: a new direction for clinical practice and research? Hong Kong Journal of Psychiatry $11,23-26$.

Shum, D., Ungvari, G.S., Tang, W.K., Leung, J.P., 2004. Performance of schizophrenia patients on time-,event-, and activity-based prospective memory tasks. Schizophrenia Bulletin 30, 693-701.

Simons, J.S., Scholvinck, M.L., Gilbert, S.J., Frith, C.D., Burgess, P.W., 2006. Differential components of prospective memory? Evidence from fMRI. Neuropsychologia 44, 1388-1397.

Sitskoorn, M.M., Aleman, A., Ebisch, S.J.H., Appels, M.C.M., Kahn, R.S., 2004. Cognitive deficits in relatives of patients with schizophrenia: a meta-analysis. Schizophrenia Research 71, 285-295.

Spreen, O., Strauss, E., 1991. A Compendium of Neuropsychological Tests: Administration, Norms, and Commentary. Oxford University Press, NY.

Spreen, O., Strauss, E., 1998. A Compendium of Neuropsychological Tests: Administration, Norms, and Commentary, 2nd ed. Oxford University Press, New York.

Szokr, A., Schurhoff, F., Mathieu, F., Meary, A., Ionescu, S., Leboyer, M., 2005. Tests of executive functions in first-degree relatives of schizophrenic patients: a metaanalysis. Psychological Medicine 35, 771-782.

Trandafir, A., Meary, A., Schurhoff, F., Leboyer, M., Szoke, A., 2006. Memory tests in firstdegree adult relatives of schizophrenic patients: a meta-analysis. Schizophrenia Research 81, 217-226.

Tuulio-Henriksson, A., Haukka, J., Partonen, T., Varilo, T., Paunio, T., Ekelund, J., Cannon, T.D., Meyer, J.M., Lonnqvist, J., 2002. Heritability and number of quantitative trait loci of neurocognitive functions in families with schizophrenia. American Journal of Medical Genetics, Part B 114, 483-490.

Twamley, E.W., Woods, S.P., Zurhellen, C.H., Vertinski, M., Narvaez, J.M., Mausbach, B.T., Patterson, T.L., Jeste, D.V., 2008. Neuropsychological substrates and everyday functioning implications of prospective memory impairment in schizophrenia. Schizophrenia Research 106, 42-49.

Wang, Y., Chan, R.C.K., Hong, X., Ma, Z., Yang, T., Guo, L., Yu, X., Li, Z., Yuan, Y., Gong, Q., Shum, D., 2008a. Prospective memory in schizophrenia: further clarification of nature of impairment. Schizophrenia Research 105, 114-124. 
Wang, Y., Chan, R.C.K., Yu, X., Shi, C., Cui, J., Deng, Y., 2008b. Prospective memory deficits in subjects with schizophrenia spectrum disorders: a comparison study with schizophrenic subjects, psychometrically defined schizotypal subjects, and healthy controls. Schizophrenia Research 106, 70-80.

Wechsler, D., 1987. Wechsler Memory Scale Manual. Psychological CorpNew York.

Whalley, H.C., Whyte, M., Johnstone, E.C., Lawrie, S.M., 2005. Neural correlates of enhanced genetic risk for schizophrenia. The Neuroscientist 11, 238-249.
Whyte, M.C., McIntosh, A.M., Johnstone, E.C., Lawrie, S.M., 2005. Declarative memory in unaffected adult relatives of patients with schizophrenia: a systematic review and meta-analysis. Schizophrenia Research 78, 13-26.

Woods, S.P., Twamley, E.W., Dawson, M.S., Narvaez, J.M., Jeste, D.V., 2007. Deficits in cue detection and intention retrieval underlie prospective memory impairment in schizophrenia. Schizophrenia Research 90, 344-350. 